\title{
Formation of the Foundations of Ecological and Economic Culture in Preschoolers in the Conditions of a Megalopolis
}

\author{
Roza M. Sherayzina 1[ORCID 0000-0002-7358-0689], \\ Marina V. Alexandrova 1[ORCID 0000-0003-1745-4730], \\ Marina S. Zadvornaya ${ }^{2 *[O R C I D ~ 0000-0002-6352-3111] ~}$
}

\author{
${ }^{1}$ Yaroslav-the-Wise Novgorod State University, Veliky Novgorod, Russia \\ ${ }^{2}$ Saint Petersburg Academy of Postgraduate Pedagogical Education, Saint Petersburg, Russia \\ marina-slavovna@yandex.ru
}

\begin{abstract}
In the modern world, the problem of human ecological and economic culture is defined as a global challenge of social significance. It is no coincidence that the first decades of the 21 st century were marked by an increased scientific interest in the study of the problem of ecological and economic education of preschoolers, as well as the development of innovative educational projects and technologies in this area by practicing teachers. In this context, starting from the preschool level of education, the formation of the foundations of ecological and economic culture in preschoolers in the conditions of a metropolitan city is of particular importance. It is possible to ensure the quality of the solution to the tasks set, subject to the high professional competence of teachers, their mastery of modern technologies for the formation of the foundations of ecological and economic culture. The analysis of dissertation research indicates the presence of scientific works of Russian and foreign scientists devoted to the study of this problem, and indicates the insufficiency of its consideration. The scientific and practical relevance of the indicated problem is confirmed by the traditional approach to this problem, the need to expand the use of partial programs for the formation of ecological and economic education in a metropolis, which have a certain potential in the development of the educational process. Despite the absence of conditions, it is necessary to search for directions in this direction. The article presents the results of a study that made it possible to identify positive and negative trends in the activities of teachers in the formation of the foundations of the ecological and economic culture of children in a metropolis. The content of educational programs in environmental and economic education has been studied; their correspondence to the originality of the metropolitan areas and the socialization of modern preschoolers under the influence of the family was determined. The tendencies that characterize the priority directions, forms, methods, pedagogical technologies and effective cultural practices of the formation of the foundations of ecological and economic culture in interaction with the parents of preschoolers are revealed; satisfaction of parents' requests, the possibility of obtaining specific recommendations for the successful socialization and individualization of a child's development in accordance with the target guidelines of preschool education.
\end{abstract}

Keywords: environmental problem, environmental education, socialization of preschoolers

\section{INTRODUCTION}

In the modern world, the problem of human ecological and economic culture is defined as a global challenge of social significance. Russia can achieve sustainable development only by solving environmental, social and economic problems, therefore, the formation of the ecological and economic culture of the younger generation is becoming one of the important tasks of preschool education.

In the psychological and pedagogical literature, Russian scientists (S.V. Alekseev, M.K. Ibraimova, 
N.N. Kondratyeva, P.G. Samorukova, E.F. Terentyeva, A.M. Fedotov, I.A. Khaidurova, etc.) note the integration of the ecological and economic components of culture; (V.P. Arsentyeva, N.N. Veresov, S.N. Glazachev, T.A. Markova, M.Yu. Popova, N.A. Ryzhova, I.G. Ryabova, etc.) carried out a number of research on the formation of ecological and economic culture.

In the study by I.G. Ryabova, which is dedicated to the environmental education of children of primary school age, the author notes that only now is the formation of continuous environmental education taking place, which should include all levels of education, including the preschool level. S.N. Glazachev highlighted the principles of environmental education: "the development of environmental culture of an individual and society as an intellectual and practical experience of preserving and improving the state of the socio-natural environment; complementary use of the teaching function of a variable and protected nature; combination of consideration of nature conservation problems on a global scale with feasible participation in their solution on a local scale" [1]. E.V. Kozlova, A.A. Smolentseva, L.A. Golub consider economic education as a component of a person's general culture, which involves the formation of economic thinking, reasonable economic needs, an economically conscious attitude to work, nature, material values. A.D. Shatova notes the significant impact on economic education and the upbringing of children of cultural and national characteristics of a metropolian city, which must be taken into account when developing the content and technology for the implementation of economic education. However, in a conditions of a metropolis, this research topic has not been sufficiently studied. Analysis of studies by Russian and foreign scientists shows that in all large metropolitan areas there are the same problems, so it becomes possible to specify the content of environmental and economic education, taking into account the specifics of a metropolis in which children of preschool age also live [2].

The general content of environmental and economic education is the idea of the relationship and interaction between human and nature, as well as the development of the economy, subject to the reasonable consumption and use of resources [3].

In Saint Petersburg, preschool educational organizations are actively involved in various environmental and economic educational international projects, large enterprises of the city are involved in environmental and economic education (SUE Vodokanal, Lenenergo, etc.). This is connected with the problem of forming the foundations of ecological and economic culture as a global problem of social significance, which is significant for metropolises.

The modern interpretation of the term "ecological and economic culture" in relation to a child implies a complex personal education, which includes the initial level of formation of ecological and economic ideas, value orientations, personal qualities and experience of the mastered methods of children's activities of ecological and economic orientation. In this case, the concept of "culture" is used in the meaning of activity, practice in a particular activity, as an element of socialization of the personality of a preschooler, which is a component of preschool education [4].

Preschool age is sensitive for the formation of the foundations of the scientific worldview and will contribute to the successful formation of the ecological and economic ideas of preschoolers, taking into account the peculiarities of living in a metropolis [5].

Russian scientist B.S. Gershunsky in his works noted that since the 1990s and to this day, an important area in the preschool education system is environmental and economic education [6]. In this connection, a sufficient number of partial programs of ecological and economic content have been developed.

N.A. Ryzhova analyzed the existing partial programs, which she conditionally identified in three groups of different orientations: ecological, aestheticcultural-ecological and socio-ecological [7].

The programs of the first group deal with issues of classical ecology (N.N. Kondratyeva, "We" ("My")), in which the main attention is paid to the analysis of the relationship of living organisms with the environment; the formation of a holistic view of nature and the place of human in it, an ecological worldview, a responsible attitude not only to the environment, but also to one's health (N.A. Ryzhova, "Nature is our home" ("Nash dom - priroda")). The programs of the second group included partial programs (V.I. Ashikov, S.G. Ashikova, "Sevenflower" ("Semicvetik"); I.G. Belavina, N.G. Naydenskaya, "The planet is our home" ("Planeta - nash dom"), T.I. Popova, "The world around us" ("Mir vokrug nas")), the main task of which is the moral education of children. Objects of nature are considered in the programs from the 
standpoint of four "elements": earth, air, water, fire. The third group consisted of programs (N.N. Veresov, "We are Earthlings" ("My zemlyane"), T.V. Potapova, "Kindergarten of the XXI century" ("Detskij sad XXI veka")), which consider a complex of social issues. In addition, to one degree or another, these issues are reflected in complex programs such as "Rainbow", "Childhood", "Development", “Origins" ("Raduga”, "Detstvo", "Razvitie", "Istoki”).

Currently, in the practice of preschool education in Saint Petersburg, a partial educational program "Economic education of preschoolers: the formation of the prerequisites for financial literacy" is being actively tested (Yu.A. Aksenova, V.E. Davydova, I.L. Kirillov, I.S. Mishchenko, A.D. Shatova). The program is focused on family economic literacy and the formation of elementary economic skills in older preschool children. The goal of the program is "to educate a person who is able and willing to work hard and actively, earn money honestly and loves their country" [8].

It should be noted that in most preschool educational institutions, the issues of forming the foundations of ecological and economic culture are included in the content section of the educational program of a particular preschool educational institution $(66.9 \%)$, are present in the target section $(55.9 \%)$, in the expected results (53.4\%). Educational programs for half of the respondents $(50.8 \%)$ contain links to modern partial environmental and economic programs.

So, in the course of analyzing the scientific literature, studying the research of foreign and Russian scientists, we identified the main problem identifying the effectiveness of the activities of preschool teachers in the formation of the ecological and economic culture of preschoolers in a metropolis.

\section{MATERIALS AND METHODS}

Based on the identified problem, the purpose of this work was to identify the effectiveness of the activities of preschool teachers in the formation of the foundations of ecological and economic culture among preschoolers in a metropolis: in the aspect of solving the problems of socialization of children; determination of the deficiencies of professional competence in the implementation of pedagogical support, requiring correction in the system of additional professional education; development of a diagnostic technique based on questionnaires, expert assessment and pedagogical diagnostics.
The research was carried out in two interrelated directions:

- through a questionnaire survey of regional methodologists of Information and Methodological Centers and an expert assessment of the content of their sites;

- through questionnaires of managers, selfanalysis of the effectiveness of teachers in this area on the basis of pedagogical diagnostics.

The first direction of the study made it possible to:

- reveal the general picture of the organization of the formation of the foundations of ecological and economic culture in preschool children in preschool educational establishments in a metropolis;

- to evaluate the work carried out by information and methodological centers (hereinafter - IMC), aimed at increasing the professional competence of teachers and the quality of advice to parents of preschoolers on environmental and economic culture.

The second direction of the study opened up the opportunity:

- to analyze the effectiveness of teachers' activities in forming the foundations of ecological and economic culture in the educational space of St. Petersburg as the second largest metropolis in Russia, where the socialization of preschoolers is due to the peculiarities of the development of a modern metropolis;

- to identify the inclusion in the content of the educational program of a particular preschool educational institution of partial programs for the formation of the foundations of an ecological and economic culture with an orientation towards the individual needs of children and cooperation with families of preschoolers;

- to analyze the accumulated experience in the formation of the foundations of ecological and economic culture (pedagogical diagnostics, developing the subject-spatial environment, variable forms, methods, methods and means of implementing the program in the educational process), as well as the interaction of the teaching staff with the families of pupils and providing them advice; 
- to determine the level of professional competence of teachers in the formation of the foundations of ecological and economic culture in preschoolers.

The methodological basis of the research was: progressive achievements in the field of natural science, revealing the essence, goals, content and technologies of environmental education of preschoolers (V.P. Arsentieva, N.N. Veresov, I.A. Nikolaeva, Z.P. Plokhiy, P.G. Samorukova, I.A. Khaidurov and others); economic education (L.N. Galkina, O.V. Dybina, L.M. Klarina, E.A. Kurak, A.A. Smolentseva, A.D. Shatova).

The research methods were: theoretical analysis of scientific literature and regulatory documents; questioning, as the main research method with the assessment of indicators - indicators of the effectiveness of teachers' activities in the formation of their foundations of ecological and economic culture in a metropolis; observation; study of programs; the method of expert assessment of information sites of the IMC of different districts of St. Petersburg; methods of self-assessment of the effectiveness of teachers' activities in the educational process based on pedagogical diagnostics; analysis of experimental data.

In the course of the study, a rating of the main problems and reasons for the insufficient effectiveness of the formation of the foundations of ecological and economic culture was determined, which in a metropolis is due to a number of reasons:

- insufficient level of ecological and economic culture, a set of global ecological and economic social problems of modern mankind;

- lack of diagnostic tools and resource material for teachers to implement a holistic educational process [9];

- low ecological and economic culture of parents, miscalculations of family education;

- lack of conditions and the necessary developing subject-spatial environment [1012];

- lack of professional competence of teachers in creating space for the formation of cultural practices when interacting with the family on issues of ecological and economic culture [13].

\section{RESULTS}

In 2020, the authors of the article conducted a study in which 29488 preschool children and their parents, 2214 teachers, 222 representatives of the administrative and managerial staff took part.

The study showed that the methodologists for preschool education of the IMC are building a system of methodological support for preschool teachers on the formation of the foundations of ecological and economic culture among preschoolers through events - seminars, round tables (72-78\%); refresher courses are also being implemented.

Figure 1 presents the generalized results of an expert assessment of the content of the sites of regional IMCs on the organization of work aimed at increasing the professional competence of teachers and the quality of advice to parents of preschoolers in the formation of the foundations of ecological and economic culture in children on the basis of preschool education, and allow us to state that at present this resource not used enough.

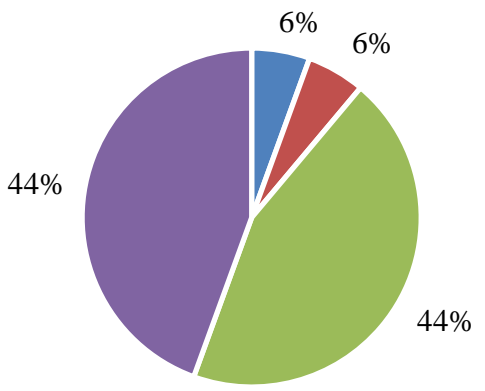

- Excellent - Good - Satisfactory - Unsatisfactory

Figure 1. Expert assessment of the content of the sites of regional IMC in order to provide methodological support for the formation of the foundations of ecological and economic culture in preschoolers

Source: Compiled by the authors based on research results

The solution to the problem of the lack of diagnostic tools and resource material was facilitated by the expansion of the volume and options for methodological assistance to preschool teachers.

In the course of the study, the most effective forms and methods for the formation of an ecological and economic culture in preschool educational institutions (contests of crafts, drawings (59\%); productive and educational and research activities (56\%); actions (51\%) and projects of ecological and economic content (49\%); an example of responsible behavior of adults in environmental and economic relations (49\%)). The use of project activities $(83.9 \%)$, and the creation of a developing subject-spatial environment in preschool educational institutions $(81.4 \%)$ are recognized as important 
conditions for the formation of an ecological and economic culture.

The teachers realize the importance of interaction with the family in the formation of the foundations of ecological and economic culture: joint parentchild events, actions, projects (58\%); individual consultations with a personal visit to kindergarten (42\%) and participation in kindergarten activities as participants $(42 \%)$.

Pedagogical support of the formation of ecological and economic culture in preschoolers involves purposeful activity to create conditions for the implementation of this task through the interaction of teachers with children and their parents [14]. The leading position for assessing the performance of teachers in this matter is based on the study of this activity from different angles: software; the readiness of teachers and pre-school teachers to implement the tasks of ecological and economic education, taking into account the uniqueness of the life of the megalopolis; the level of development of preschool children in the field of the foundations of ecological and economic culture; interaction with parents and their contentedness.

The effectiveness of the activities of preschool teachers in the formation of the foundations of ecological and economic culture $(61 \%)$ was rated at 4 points on a 5-point scale. The data are presented in Figure 2.

In addition, based on the questioning of teachers, data were obtained on their understanding $(75 \%)$ of the deterioration of the ecological and economic situation in the country.

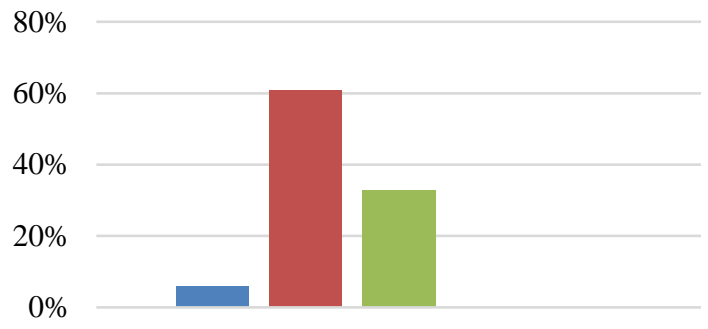

$\square 5$ points $\square 4$ points $\square 3$ points $\backsim 2$ points $\square 1$ point

Figure 2. Diagram for assessing the effectiveness of teachers' activities in the formation of the foundations of ecological and economic culture in preschoolers

Source: Compiled by the authors based on research results

The heads of preschool educational institutions independently determined the readiness of teachers to present the accumulated experience on this topic, the results are shown in Figure 3.

From Figure 3 it follows that $49.2 \%$ of respondents are ready to publish an article on the problem under study. This testifies to the comprehension and generalization of the work experience that is conducted in preschool educational institutions, and the positive results obtained. $41.5 \%$ are ready to organize and participate in webinars dedicated to this problem; $33.9 \%$ agree to take part in the round table, to discuss these problems in a metropolis. So, only $11.0 \%$ are ready to speak at a scientific-practical conference, and $5.9 \%$ are ready to conduct trainings. $10.0 \%$ of the preschool educational institutions participating in the study are not ready to broadcast their work experience for various reasons.
Other: not ready

Other: publication on the official website of the PEI

Other: project presentation

Other: presentation of manuals

Publishing an article

Webinar (organization/participation)

Scientific and practical conference

Training

Round table

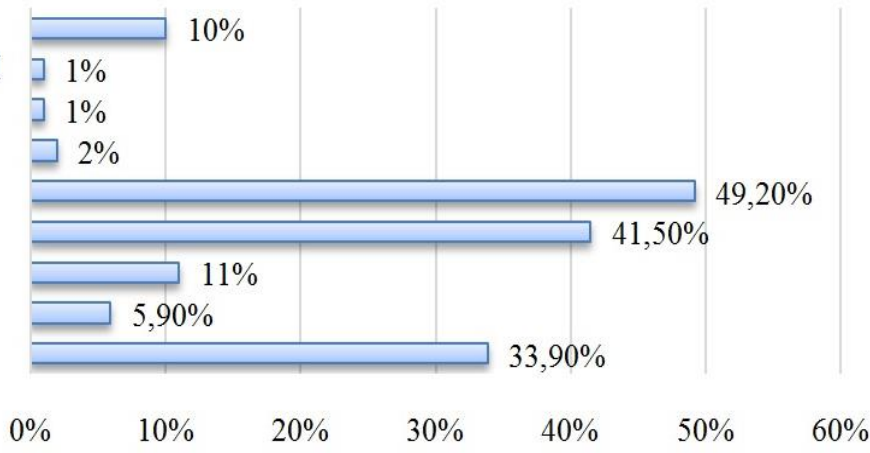

Figure 3. The readiness of teachers to present their experience in shaping the foundations of ecological culture in a metropolis

Source: Compiled by the authors based on research results

Thus, according to Russian scientists, "today there is a demand for a professional-oriented, creative, competent teacher, capable not only of forming knowledge and skills, but also of realizing his personal potential in the context of the modern system of education and training of preschool children" [15]. 


\section{DISCUSSION}

The conducted research makes it possible to note that the formation of the foundations of ecological and economic culture is included in the content section of the educational program of the preschool educational institution.

The analysis of the accumulated experience in the formation of ecological and economic culture in terms of pedagogical diagnostics, the creation of a developing subject-spatial environment, the use of variable forms, methods, methods and means of implementing the program in the educational process, as well as the interaction of the teaching staff with the families of pupils and providing them with advice indicates its effectiveness.

In the course of the study, the rating of the main problems and reasons for the insufficient effectiveness of the education of the foundations of ecological and economic culture in accordance with the professional standard was determined. It was found that the difficulties of implementing programs of environmental and economic orientation in preschool educational institutions are associated with a lack of culture of adults, difficulties in working with the family; living conditions in the metropolis; the complexity of using interactive methods. In addition, the lack of competence among teachers in matters of environmental and economic culture and educational programs in this direction, as well as methodological support to them and lack of funding cause tension.

The identified deficiencies can be compensated for through the development and implementation of additional professional training programs in the system of additional professional education in $\mathrm{St}$. Petersburg, as well as a broad discussion of the problem at scientific and practical conferences, round tables, webinars, etc.

All the material presented in the course of the study makes it possible to draw a conclusion about the satisfactory quality of professional activity on this issue, which ensures a stable improvement in the quality of life of citizens in a metropolitan city.

\section{CONCLUSION}

The results of the study led to the following conclusions:

- the formation of the foundations of ecological and economic culture is included in the content section of the educational program of a preschool educational establishment;

- the most effective forms and methods for the formation of the foundations of ecological and economic culture among preschoolers have been determined;

- effective pedagogical activity of preschool educational institutions on this issue is possible only with the inclusion of parents.

Thus, the goal has been achieved, the tasks have been solved and the theoretical provisions set forth in the works of Russian scientists in the formation of the foundations of ecological and economic culture have been confirmed.

\section{AUTHORS' CONTRIBUTIONS}

Roza M. Sherayzina substantiated the research concept; Marina V. Alexandrova conducted a comparative analysis; Marina S. Zadvornaya summarized the research results and formulated conclusions.

\section{REFERENCES}

[1] I.A. Donina, E.V. Vezetiu, "Factors of forming regional policy: expectations of consumers of educational services", The European Proceedings of Social \& Behavioural Sciences, 2019, vol. 77, pp. 440-445. DOI: 10.15405/epsbs.2019.12.05.53

[2] S.N. Kashtanova, E.Y. Medvedeva, V.A. Kudryavtsev, E.A. Olkhina, N.V. Karpushkina, "The monitoring of the universities' activities as a basis for inclusive higher education strategic development", Espacios, 2017, vol. 38(56), p. 23.

[3] J. Gorelova, N. Khilko, "Organizational Forms of Implementation of Pedagogical Technologies in the Media Education System", International Journal of Media and Information Literacy, 2020, vol. 5(1), pp. 31-36. DOI: 10.13187/ijmil.2020.1.31

[4] A. Kirkwood, L. Price, "Technology-enhanced learning and teaching in higher education: what is 'enhanced' and how do we know? A critical literature reviews", Learning, Media and Technology, 2014, vol. 39(1), pp. 6-36. DOI: 10.1080/17439884.2013.770404

[5] M.G. Sergeeva, V.N. Skvortsov, A.S. Sokolova, S.V. Rachek, N.G. Poyarkov, E.V. Konysheva, I.V. Poliakova, "Planning individual educational 
trajectory in continuing education", International Journal of Recent Technology and Engineering, 2019, vol. 8(3), pp. 654-658. DOI: 10.35940/ijrte.B2637.098319

[6] M.S. Zadvornaya, N.V. Litvinova, S.R. Milonova, "New formats of accompanying parents of pupils in a preschool educational organization" [Novye formaty soprovozhdeniya roditeley vospitannikov v doshkol'noy obrazovatel'noy organizatsii], Questions of Pedagogy [Voprosy Pedagogiki], 2020, vol. 7(2), pp. 43-49. (In Russ.).

[7] A. Suominen, M. Seppänen, O. Dedehayir, “A bibliometric review on innovation systems and ecosystems: a research agenda", European Journal of Innovation Management, 2019, vol. 22(2), pp. 335-360. DOI: 10.1108/EJIM12-2017-0188

[8] A.D. Shatova, "Economic education of preschoolers: the formation of the prerequisites for financial literacy. Approximate partial educational program of preschool education" [Ekonomicheskoye vospitaniye doshkol'nikov: predposylki formirovaniya finansovoy gramotnosti Primernaya partsial'naya obrazovatel'naya programma doshkol'nogo obrazovaniya], Moscow, 2018. (In Russ.).

[9] J.M. Jenkins, A.A. Whitaker, T. Nguyen, W. Yu, "Distinctions Without a Difference? Preschool Curricula and Children's Development", Journal of Research on Educational Effectiveness, 2019 , vol. 12(3), pp. 514-549. DOI: $10.1080 / 19345747.2019 .1631420$

[10]I. Mcloughlin, S. Davenport, Y. Mcnicoll, J. Cornford, "Data-driven innovation in the social sector in Australasia-data ecosystems and interpretive communities", Public Money \& Management, 2019, vol. 39(5), pp. 327-335. DOI: $10.1080 / 09540962.2019 .1611235$

[11]E.V. Maltseva, D.L. Kolomiets, N.D. Glizerina, L.V. Kurochkina, I.N. Andreeva, O.B. Shestakova, "Technologies of organizing prospective teachers' practical training on the basis of competence approach", Review of European Studies, 2015, vol. 7(8), pp. 35-43. DOI: $10.5539 /$ res.v7n8p43

[12] F. Villar, M. Celdrán, "Learning in Later Life: Participation in Formal, Non-Formal and Informal Activities in a Nationally Representative Spanish Sample", European Journal of Ageing, 2013, vol. 10(2), pp. 135144. DOI: $10.1007 / \mathrm{s} 10433-012-0257-1$

[13] E.A. Fedorova, S.O. Musienko, F.Yu. Fedorov, O.Yu. Rogov, "Assessment of the Quality of Education in Russian Regions", Regional Economics: Theory and Practice, 2018, vol. 16(2-449), p. 249-262. (In Russ.). DOI: $10.24891 /$ re.16.2.249

[14] M.S. Zadvornaya, "Formation and development of teachers of preschool educational organization in the process of continuous learning", Uchenye Zapiski Universiteta imeni P.F. Lesgafta, 2019, vol. 2(168), pp. 138-142. (In Russ.).

[15]R.M. Sherayzina, M.S. Zadvornaya, "The profession of the teacher of preschool education in the modern information society", Continuing Education [Nepreryvnoe Obrazovanie], 2020, vol. 4(34), pp. 14-18. (In Russ.). 